\title{
Initial validation of ENVISAT/SCIAMACHY columnar CO by FTIR profile retrievals at the Ground-Truthing Station Zugspitze
}

\author{
R. Sussmann ${ }^{1}$ and M. Buchwitz ${ }^{2}$ \\ ${ }^{1}$ IMK-IFU, Forschungszentrum Karlsruhe, Garmisch-Partenkirchen, Germany \\ ${ }^{2}$ Institute of Environmental Physics (iup), University of Bremen, Bremen, Germany \\ Received: 13 July 2004 - Published in Atmos. Chem. Phys. Discuss.: 3 February 2005 \\ Revised: 11 April 2005 - Accepted: 19 May 2005 - Published: 17 June 2005
}

\begin{abstract}
Carbon monoxide vertical profile retrievals from ground-based solar FTIR measurements at the Permanent Ground-Truthing Station Zugspitze $\left(47.42^{\circ} \mathrm{N}, 10.98^{\circ} \mathrm{E}\right.$, 2964 m a.s.1.), Germany are used to validate columnar CO retrieved from ENVISAT/SCIAMACHY spectra (WFMDOAS version 0.4). The WFM-DOAS retrievals of CO include an empirical column scaling factor of 0.5. Therefore, not absolute column levels are validated, but the proper response of the SCIAMACHY retrievals to the atmospheric inter-annual variability is quantitatively assessed in comparison to the Zugspitze FTIR results. Although CO WFMDOAS data for only 33 days were available for this study (data covering January-October 2003), it is possible to retrieve information on the $\mathrm{CO}$ annual cycle $(\approx 10 \%$ amplitude $)$ in a statistically significant fit out of the scatter of the SCIAMACHY WFM-DOAS data. To obtain this, all pixels within a minimum radius of $2000 \mathrm{~km}$ around Zugspitze had to be averaged for each day.
\end{abstract}

\section{Introduction}

Carbon monoxide $(\mathrm{CO})$ is one of the key reactive species in troposheric chemistry (IPCC, 2001). The investigation of its global distribution has again gained high-priority interest only recently, due to the detection of its hitherto unrecorded and probably unprecedented column enhancements by up to $>50 \%$ for several months in the 1998 northern hemisphere (Yurganov et al., 2004), and similar follow-on anomalies found in 2002 and 2003. This has been assessed quantitatively by a group of ground-based solar FTIR (Fourier Transform Infrared) spectrometry sites operated within the NDSC (Network for the Detection of Stratospheric Change) complemented by in-situ surface-sampling sites of the GAW

Correspondence to: R. Sussmann

(ralf.sussmann@imk.fzk.de)
(Global Atmosphere Watch) network. These ground networks are performing with high precisions which are better than 2-3\% (FTIR) and better than 5\% (in situ), respectively.

Currently, there is only one fully validated space-borne remote sounder that can add information on the global distribution of $\mathrm{CO}$ to the highly precise ground-based networks, i.e., the MOPITT (Measurements Of Pollution In The Troposphere) instrument mounted on the EOS-Terra platform (Deeter et al., 2003). Meanwhile, another satellite instrument has achieved the potential to retrieve global information on CO, i.e., the Scanning Imaging Absorption Spectrometer for Atmospheric CHartographY (SCIAMACHY), which is a UV/visible/NIR spectrometer onboard ENVISAT launched in 2002 (Bovensmann et al., 1999). In this paper we focus on the initial validation of the SCIAMACHY scientific total column product for the species CO (WFM-DOAS, ver. 0.4), retrieved at the University of Bremen (Buchwitz and Burrows, 2004; Buchwitz et al., 2004). A set of CO columns for 33 different days out of the time span JanuaryOctober 2003 has been released to the public in early 2004 via the internet (http://www.iup.physik.uni-bremen. de/sciamachy/NIR_NADIR_WFM_DOAS/). This scientific product plays a key role for the users community, since there has been no operational SCIAMACHY product for $\mathrm{CO}$ released by ESA yet.

A first validation study for the WFM-DOAS (WFMD) CO retrievals had been performed by comparing with data of the MOPITT satellite instrument. A highly consistent behavior relative to MOPITT had been found in the capability to detect highly elevated $\mathrm{CO}$ columns, e.g., a plume from biomass burning (Buchwitz et al., 2004). During this study, an empirical scaling factor of 0.5 has been established for the WFMD $\mathrm{CO}$ column retrievals which resulted from an adaptation to the MOPITT CO data (Buchwitz et al., 2004). Therefore, it is no issue for current validation studies to assess the overall absolute accuracy of the WFMD CO columns. The issue of validation is therefore now to asses the ability of the

(C) 2005 Author(s). This work is licensed under a Creative Commons License. 
WFM-DOAS retrievals to monitor the real atmospheric variability of CO columns in a realistic manner.

In this paper we want to promote the validation of $\mathrm{CO}$ by comparing the WFMD retrievals to the ground-based correlative solar FTIR data of the clean air site Zugspitze. The question to be addressed in this study, is whether the WFMD retrievals can reflect the natural variability of $\mathrm{CO}$ above the clean air site Zugspitze, which is dominated by the annual cycle for this species.

\section{The correlative ground data set from Zugspitze solar FTIR}

For details of the SCIAMACHY WFMD CO retrievals in the near-infrared spectral domain, the reader is referred to Buchwitz and Burrows (2004) and Buchwitz et al. (2004). Our initial validation study is performed using the correlative ground-based data that are being recorded by the NDSC Primary Status solar FTIR instrument at the Zugspitze $\left(47.42^{\circ} \mathrm{N}, 10.98^{\circ} \mathrm{E}, 2964 \mathrm{~m}\right.$ a.s.1.) continuously. The Zugspitze FTIR-instrument and retrieval-set up has been described in detail elsewhere (Sussmann and Schäfer, 1997; Sussmann, 1999). Briefly, a high-resolution Bruker IFS 120 HR Fourier Transform Spectrometer is operated with an actively controlled solar tracker, and liquid-nitrogen cooled $\mathrm{MCT}$ and $\mathrm{InSb}$ detectors. For the CO retrievals, interferograms with a maximum optical path difference (OPD) of $250 \mathrm{~cm}$ are recorded. Typically, 6 individual interferograms are averaged to obtain one spectrum, leading to a total integration time of approximately $15 \mathrm{~min}$.

The Zugspitze CO columns are retrieved by integrating of profile retrievals which are performed by a simultaneous spectral fit in 3 micro-windows, i.e., 2057.7850-2057.9100 $\mathrm{cm}^{-1}, \quad 2069.6150-2069.7100 \mathrm{~cm}^{-1}$, and $2157.3300-2159.1500 \mathrm{~cm}^{-1}$. Note that the spectral boundaries of these micro-windows have been slightly modified as compared to previous publications (Pougatchev and Rinsland, 1995; Rinsland et al., 2000), in order to minimize systematic spectral residuals. We are using the optimalestimation method as implemented in the SFIT2-retrieval software provided by NASA, and established in collaboration with NIWA (Pougatchev et al., 1995). The HITRAN2000 molecular line parameters compilation was used

(Rothmann et al., 2003), and daily p-T-profiles from the Munich radiosonde station (located $80 \mathrm{~km}$ to the north of the Zugspitze) have been utilized. For a-priori information, a CO vertical volume mixing ratio profile obtained from the MOPITT team (L. N. Yurganov, personal communication, 2002) was adopted. The covariances for the $\mathrm{CO}$ mixing ratio profile vectors were assumed to be diagonal with the assumed uncertainties increasing by a factor of 2 below $30 \mathrm{~km}$ relative to their values above this altitude. Absolute uncertainties were then tuned empirically to optimize the trade off between gaining information content and avoiding oscillating retrievals. The accuracies/precisions for total vertical column $\mathrm{CO}$ retrievals via integrated vertical profile retrievals from ground-based FTIR measurements are understood and well characterized (Pougatchev and Rinsland, 1995; Rinsland et al., 2000). The actual numbers depend somewhat on changing geophysical parameters like the actual solar zenith angle. The random errors for single column retrievals have been estimated to be within $\pm 2.5 \%$ and systematic errors to range from \pm 2.5 to $\pm 5 \%$ (Pougatchev and Rinsland, 1995; Rinsland et al., 2000).

\section{Approach for initial validation}

The retrieval of WFMD ver. 0.4 total column products of CO includes an empirical column scaling factor, i.e., WFMD CO data have been scaled to match MOPITT columns and a final scaling factor of 0.5 has been fixed for WFMD ver. 0.4 CO retrievals (Buchwitz et al., 2004). Therefore, focus is put in our study on relative accuracy, i.e., investigating whether the atmospheric variabilities above the Zugspitze, which are dominated by the annual cycle for these species, can be retrieved from the SCIAMACHY data.

Individual WFMD retrievals in the near-infrared spectral domain are showing a significant scatter. This is because the small spectral signals are only slightly above the noise level, and because of the occurrence of systematic spectral residuals which are not understood yet (Buchwitz et al., 2004). In Buchwitz et al. (2005b) several days of SCIAMACHY global CO data over land have been compared with the operational level-2 CO column data product of MOPITT (ver. 3 ). It has been show that on average the difference between the two data sets is about $10 \%$. The largest differences have been found over the Southern Hemisphere outside Antarctica, where SCIAMACHY may overestimate MOPITT by up to about $30 \%$ (over the Northern Hemisphere the agreement is much better). The standard deviation of the difference is in the range $0.4-0.610^{18} \mathrm{~cm}^{-2}$, i.e., about $30 \%$. This standard deviation of $30 \%$ is approximately equal to the expected single pixel retrieval precision of the SCIAMACHY $\mathrm{CO}$ columns. This holds for a restriction of the so-called retrieval error (see Buchwitz et al., 2004) to values below $60 \%$. A precision of about $10 \%$ is the expected theoretical limit which, however, has not yet been reached mainly for two reasons: i) The currently used fitting window only covers a small subset of the CO lines detected by SCIAMACHY resulting in a random error due to instrument noise of about $20 \%$ for an integration time of $0.5 \mathrm{~s}$ (Buchwitz and Burrows, 2004). For future versions of the retrieval algorithm we will aim at using a larger fitting window to improve the precision. ii) A quasi random error of about 5-20\% is introduced by disturbances due to variability of the atmosphere (e.g., aerosol scattering) and of the surface reflectivity not fully accounted for in the current version of the retrieval algorithm (Buchwitz and Burrows, 2004). 
The CO retrieval from the SCIAMACHY spectra is complicated by an ice layer that grows on the (cooled) channel 8 detector. Every few month a decontamination procedure is performed to get rid of the ice layer. This ice layer not only affects the channel $8 \mathrm{CO}$ retrieval but also the channel $8 \mathrm{CH}_{4}$ retrieval (see Buchwitz et al., 2005b). In Buchwitz et al. (2005b) it has been shown that the ice layer introduces a time dependent bias of the retrieved methane columns of up to about $15 \%$ (low bias) as the ice layer changes the slit function of the SCIAMACHY spectrometer. A similar time dependent bias is expected for the SCIAMACHY channel 8 $\mathrm{CO}$ columns discussed in this paper. The SCIAMACHY $\mathrm{O}_{2}$ columns are not affect by this issue (no ice layer has been observed for channel 4 used for $\mathrm{O}_{2}$ retrieval).

Having these known quality limitations in mind, our approach in this study, therefore is investigating to what extent the quality of SCIAMACHY data allows to reproduce the true variability of $\mathrm{CO}$ columns which is mainly dominated by the annual cycle above the Zugspitze, in a statistically significant manner. For this purpose, the annual cycle found by the Zugspitze FTIR column measurements is compared to the available time series of SCIAMACHY WFMD columns (data for $\approx 30$ days in the time span January-October 2003) using daily mean pixel averages within a stepwise increased selection radius around the Zugspitze ground site. The goal is to thereby stepwise reduce the scatter of the daily means by statistically averaging over increasing ensembles of pixels.

One might argue that also polluted regions may be more and more included into the ensemble while increasing the selection radius, and this could potentially be compensating the statistical effect of reducing the scatter of the daily means. However, this effect is obviously weaker than the reduction of scatter by the statistical effect of increasing the averaging ensemble, as our test in Sect. 4 below is proving (Table 1). Furthermore, we are investigating in this study whether the $\mathrm{CO}$ annual cycle can be retrieved, and in our recent study on total column and in situ series of CO (Yurganov et al., 2004), it has been found, that the annual cycles of $\mathrm{CO}$ observed at a variety of stations within the northern hemisphere, are comparable at all stations as to phase and amplitude $(\approx 10 \%$ amplitude, slightly lower for stations located within the free troposphere). This means, that increasing the selection radius for calculating daily means does not disturb the goal of obtaining a well defined annual cycle, but helps to reduce the scatter (see above).

However, we note that the above mentioned clean-air-site sinusoidal CO annual cycle (Fig. 2) with a spring maximum and a fall minimum is due to the $\mathrm{OH}$ (sink) annual cycle. For clean-air sites this periodical behavior can be perturbed by long-range transport of $\mathrm{CO}$ from biomass burning events which usually accur during summer. As an example, there was an significant enhancement at all clean air sites in $\mathrm{Au}-$ gust 2003 all over the northern hemisphere due to boreal forest fires in the high northern hemisphere (Yurganov et al., 2005). This can be seen in FTIR data of our Fig. 2. For
Table 1. Slope, slope error, and regression coefficient $R$ from the linear fit to the "Zugspitze FTIR" data, and to the SCIAMACHY $\mathrm{CO}$ data for a $2000-\mathrm{km}$ pixel-selection radius around the Zugspitze ("SCIA 2000") as shown in Fig. 3. "SCIA 1000" means a 1000-km selection radius, and "SCIA 1000_cl" is with cloud flagged pixels included.

\begin{tabular}{llll}
\hline & Slope & Slope error & $R$ \\
\hline Zugspitze FTIR & $-9.5 \mathrm{E}-4$ & $\pm 9.8 \mathrm{E}-5$ & -0.70 \\
SCIA 2000 & $-1.2 \mathrm{E}-3$ & $\pm 4.9 \mathrm{E}-4$ & -0.43 \\
SCIA 1000 & $-6.4 \mathrm{E}-4$ & $\pm 5.9 \mathrm{E}-4$ & -0.21 \\
SCIA_cl 1000 & $-4.4 \mathrm{E}-4$ & $\pm 4.3 \mathrm{E}-4$ & -0.18 \\
\hline
\end{tabular}

polluted areas, like industrialized areas and towns there is another, periodical effect contributing to the total $\mathrm{CO}$ annual cycle. It is a contribution to the boundary layer due to heating and fuel burning with a mid-winter maximum and a mid-summer minimum, see, e.g., Bayerisches Landesamt für Umweltschutz (2005). This is directly linked to in the situ emissions without transport or chemical transformation processes being involved (i.e., a similar annual-cycle effect as observed for boundary layer $\mathrm{NO}_{2}$ ).

The question is whether this third effect can become a dominant contribution to our SCIAMACHY data set including pollution hot spots within, e.g., a 2000-km selection radius around the Zugspitze (German Ruhr district, Italian Po valley), i.e., whether it should display a significantly different annual cycle compared to the clean-air site Zugspitze. We assume this not to be the case due to 3 reasons, namely i) the polluted areas are making up only a minor fraction of our 2000-km radius selection area, ii) a 2000-km radius selection area is only partially covered by SCIAMACHY pixels, and this fractional area is changing in magnitude and location, according to the availability of measurement orbits and nadir sequences, i.e., polluted areas are likely to be covered for some days and for some days not, and iii) the phases of the two periodical driving forces for the annual cycle are not very different (mid-winter versus spring maximum), see above. A quantitative independent answer to the relative magnitude of the two periodical contributions depending on selection area and columns ground altitude can not be given from measurements at the time being, keeping in mind that complementary satellite measurements by MOPITT do not show sensitivity to the boundary layer. However, for the limited number of SCIAMACHY data available for this study, we obtain evidence that increasing the selection radius for calculating daily means does support rather than hinder the goal of obtaining a well defined annual cycle comparable to that of the clean-air site Zugspitze, and helps to reduce the scatter of the satellite daily data, i.e., the relative winter time enhancement from pollution hot spots is negligible for sufficiently large selection radii (see results of Sect. 4 below). 


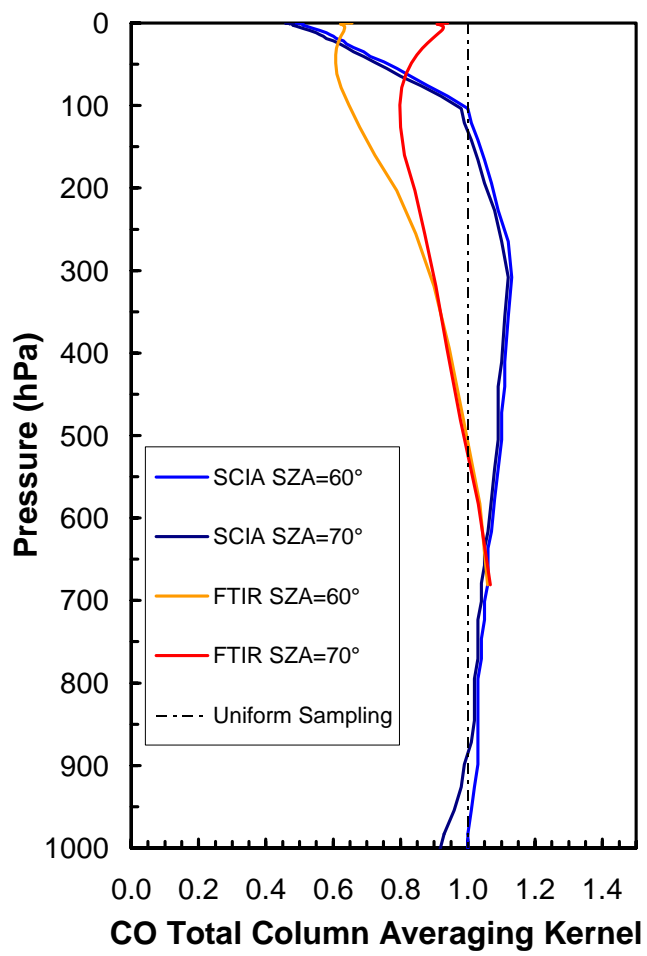

Fig. 1. Total column averaging kernels for Zugspitze FTIR and SCIAMACHY CO retrievals calculated for solar zenith angles of $60^{\circ}$ and $70^{\circ}$.

Another issue of the validation approach is how to reduce the impact of varying ground altitudes of the different satellite pixels that are averaged on one hand, and, the different altitude of the Zugspitze mountain site on the other hand. We solve this problem in a 3-steps approach: i) All individual SCIAMACHY WFMD column values are normalized to coincident dry air column values which are also available from WFMD retrievals (via $\mathrm{O}_{2}$ column retrievals). The resulting quantity is the so-called "dry air column averaged mixing ratio". This quantity does not depend on the average pixel ground level altitude, assuming a constant mixing ratio with altitude. This normalization is to account for the fact that for each day there are SCIAMACHY data available only for part of the $2000-\mathrm{km}$ radius selection area, and for changing locations, according to the limited availability of measurement orbits and nadir sequences for this individual day. Details on the $\mathrm{O}_{2}$ retrievals are given in Buchwitz et al. (2005a). Several days of global SCIAMACHY data have been compared with $\mathrm{O}_{2}$ columns computed from ECMWF surface pressures. It is shown that the mean difference of the daily data (SCIAMACHY-ECMWF) is on the order of one percent (between $-2.1 \%$ and $+0.7 \%$ ) and that the standard deviation of the difference is about $10 \%$ (between $7.9 \%$ and $12.0 \%$ ). The standard deviation is believed to be dominated by quasi random retrieval errors introduced by the variability of the atmosphere (distribution of scatterers, temperature profile vari- ations, etc.) and surface reflectivity variations not yet considered accurately enough in the retrieval algorithm (the random error due to instrument noise is well below 1\%). The estimated precision of the retrieved $\mathrm{O}_{2}$ columns of about $10 \%$ is large but significantly smaller than the variability of the $\mathrm{CO}$ columns and also significantly smaller than the $\mathrm{O}_{2}$ column variability in areas of complex surface topography such as the Alps. ii)To make the dry air column averaged mixing ratios of SCIAMACHY (unit ppbv) comparable to the FTIR column abundances above the Zugspitze (unit $1 / \mathrm{cm}^{2}$ ), both data sets are then normalized to their overall average, and these (dimensionless) "anomalies" are used for intercomparison purposes. iii) Finally, all individual Zugspitze columns are normalized to the daily mean local pressure. This is for consistency reasons, in order to make the Zugspitze ground data also independent from the actual pressure level, as the SCIAMACHY data are due to their normalization to the dry air column, see point $i$ ).

Finally, an important issue in intercomparing two different remote sounding systems (satellite versus ground) is to properly take their altitude dependent sensitivities, i.e., their averaging kernels (Rodgers, 1990) into account. In case of strongly differing kernels, neglecting the effect of different smoothing errors can result in intercomparison-errors in the order of the natural variability of the trace gas columns. However, in our case we encounter the nearly ideal situation, that the ground-based (FTIR) and satellite (SCIAMACHY) instruments are both sampling the $\mathrm{CO}$ columns with nearly the same total column averaging kernels as shown in Fig. 1, i.e., both being close to the ideal uniform sampling. There are only minor differences at higher altitudes, e.g., at the $300 \mathrm{hPa}$ level, there is a slight under-estimation of the natural variability of $\approx 10 \%$ by FTIR, and a slight overestimation of $\approx 10 \%$ by SCIAMACHY. This means that we can directly compare the retrieved columns (satellite versus ground), and the intercomparison is not impacted significantly by (differing) smoothing errors, which are in the order of $\approx 1-2 \%$ for both FTIR and SCIAMACHY, depending on the details of the $\mathrm{CO}$ covariance matrix assumed. It is noteworthy, that the SCIAMACHY retrievals are perfectly sensitive down to the lower troposphere (as the ground-based measurements are, see Fig. 1). This is due to the near-infrared spectral domain utilized for the SCIAMACHY retrievals, and is advantageous over thermal-IR satellite retrievals which are showing a reduced sensitivity in the boundary layer.

Now we want to estimate the differences in the variabilities of the Zugspitze FTIR total columns versus SCIAMACHY total columns, which are expected due to two effects, i) the different column-ground altitudes (i.e., $2964 \mathrm{~m}$ for Zugspitze FTIR and $230 \mathrm{~m}$ for the average SCIAMACHY columns ground altitude for a selection radius of $2000 \mathrm{~km}$ around the Zugspitze), and ii) the (slightly) differing averaging kernels. For this purpose, we calculated the total-column standard 
deviation using

$s t d v_{c o l}=\sqrt{\boldsymbol{a}^{T} \mathbf{S}_{\mathbf{a}} \boldsymbol{a}}$,

where the vectors $\boldsymbol{a}$ are the total column averaging kernels shown in Fig. 1, and $\mathbf{S}_{\mathbf{a}}$ is the CO covariance matrix adopted from the operational MOPITT retrieval given by Deeter et al. (2003). Thereby we obtain an expected total-column standard deviation of $27 \%$ for Zugspitze FTIR and $38 \%$ for SCIAMACHY. We note, that these numbers essentially reflect the variances given by the MOPITT $\mathbf{S}_{\mathbf{a}}$ (which is an estimation of true variability only), and the different ground altitudes of Zugspitze versus SCIAMACHY columns, i.e., they can not be compared directly to the real absolute FTIR and SCIAMACHY columns varibility. These numbers are not significantly impacted by the averaging kernels, i.e., using the ideal averging kernels $\boldsymbol{a}^{T}=(1,1, \ldots 1)$, there is only a slight change to $28 \%$ for FTIR and $36 \%$ for SCIAMACHY (in other words, the fact that there is a slight change only, is due to the small smoothing errors for both instruments, see above). However, these numbers can be interpreted in relative terms, i.e., we learn for the discussion of our results in Sect. 4, that, mainly due to the differing column-ground altitudes we would expect a higher day-to-day variability for SCIAMACHY relative to FTIR by a factor in the order of $38 / 27 \approx 1.4$.

\section{Initial validation results}

Figure 2 shows the available SCIAMACHY WFMD CO/O column anomaly data (covering 33 days in 2003); each SCIAMACHY point is the average of all pixels from one day within a $2000-\mathrm{km}$ radius around the Zugspitze, with the cloud flagged pixels removed. Note, that we did not restrict WFMD data selection to any maximum threshold in the socalled retrieval errors reported (Buchwitz et al., 2004). We did so to achieve an increased number of available data, and, thus better comparison statistics. While this leads to a single pixel standard deviation of typically $100 \%$ (compared to $30 \%$ in case of a restriction to retrieval errors below $60 \%$, see Sect. 3), we did not find any significant reduction of the scatter of daily means by testing such a restriction. Four obvious outliers in the SCIAMACHY data have ad hoc been removed for Fig. 2. Zugspitze FTIR daily mean column anomalies are shown in the same plot. A 3rd order polynomial fit to the FTIR data nicely shows the CO annual cycle with a $\approx 10 \%$ amplitude.

Figure 2 shows that the day-to-day scatter of the FTIR data is in the order of $10 \%$, while the scatter of SCIAMACHY daily data within the $2000-\mathrm{km}$ selection radius is significantly higher. While a somewhat higher columns variability (factor $\approx 1.4$ ) is anyway expected for SCIAMACHY due to the lower average ground altitude (and the slightly differing averaging kernels, see Sect. 3), the question is, whether horizontal CO inhomogeneity (hot spots) within the $2000 \mathrm{~km}$ se-

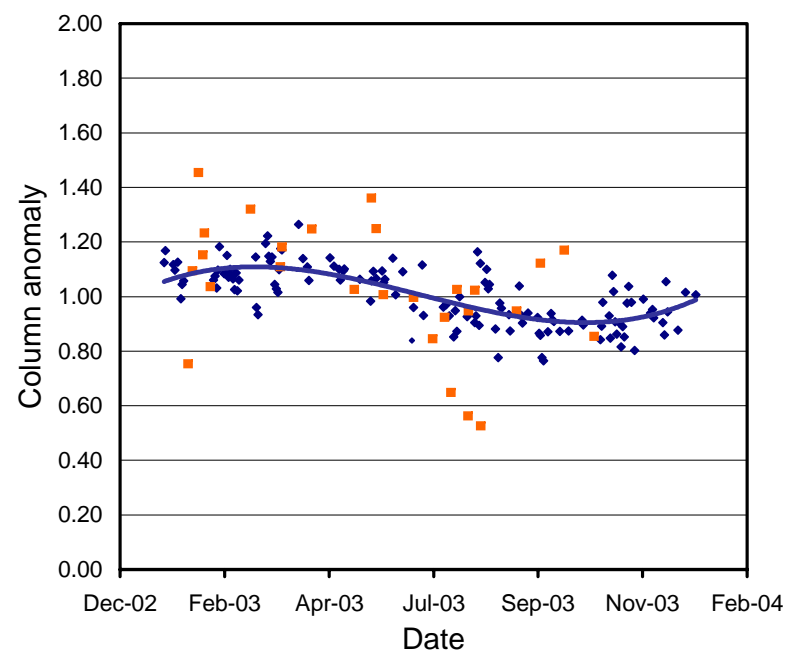

Fig. 2. Orange points: SCIAMACHY WFMD v0.4 $\mathrm{CO} / \mathrm{O}_{2}$ column anomaly: average of all pixels within a $2000-\mathrm{km}$ radius around Zugspitze for daily overpass; cloud flagged pixels and 4 outliers removed. Blue points: Zugspitze FTIR CO column anomaly: daily means of pressure corrected columns. Blue line: 3rd order polynomial fit to the Zugspitze FTIR data.

lection radius is the dominant additional cause for the scatter or the limited SCIAMACHY individual pixel precision. We investigated SCIAMACHY scenes within a large $(\approx 2000$ $\mathrm{km}$ radius) selection area around the Zugspitze for several days using the $<60 \%$ retrieval error selection rule. Thereby we found that only about $10 \%$ of the pixels showed columns that deviated by more than $30 \%$ from the average value and only about $3 \%$ deviated by more than $50 \%$. This means that the fractional area of hot spots is small, and hot spots are obviously only a minor contribution to the observed SCIAMACHY scatter for a large selection radius. This is corroborated by our investigation of a stepwise increase of the selection radius $(250-2000 \mathrm{~km}$ ) and subsequent comparison of the daily mean values for a few selected days which contained enough pixels also for the smallest selection radius. It was found that the daily average values were impacted only on the $10 \%$ level by the choice of the selection radius. Obviously, the inclusion of hot spots within a large $(2000 \mathrm{~km})$ selection radius does not significantly perturb the scatter of daily means. The advantage of such a large selection radius however, is that the order of 100 individual pixels are covered per day and this is sufficient to reduce the scatter of the daily means to a reasonable order of magnitude as shown in Fig. 2. So while a small selection radius $(250 \mathrm{~km})$ is approximately not contaminated by pollution hot spots, it just does not yield enough data for the small SCIAMACHY data set at hand, i.e., a significant fraction of days would contain none or only a few pixels and this is not enough keeping the large individual pixel precision in mind.

To investigate whether information on this annual cycle can also be retrieved from SCIAMACHY data in a statistically significant manner, a linear fit to both 


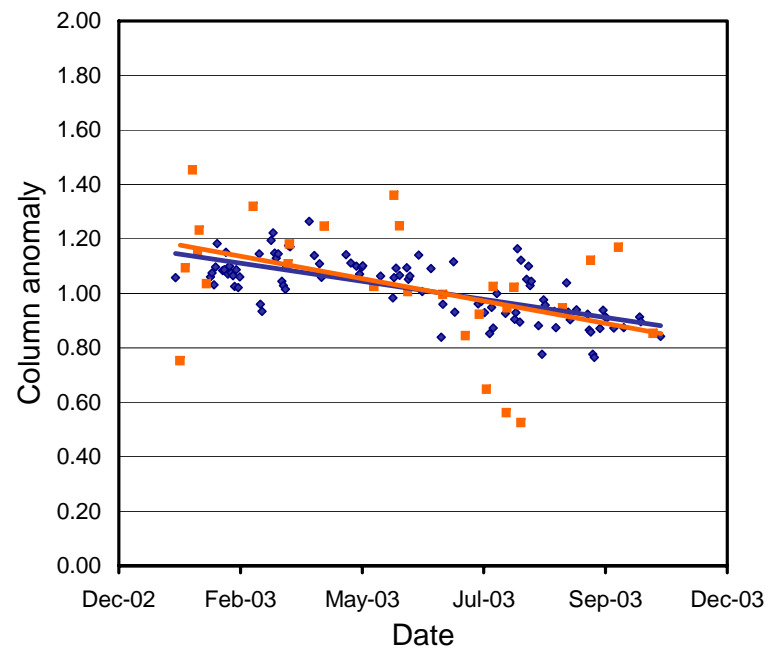

Fig. 3. Same CO data as Fig. 2, but the plotted time span of Zugspitze FTIR data is reduced to match the time span of available SCIAMACHY WFMD data. Solid lines: Linear fits. See Table 1 for the fit parameters.

SCIAMACHY and FTIR data is performed for the time span for which SCIAMACHY data are available, see Fig. 3. We used a linear fit as a proxy for the annual cycle because, contrary to the case of FTIR data (Fig. 2), a 3rd order polynomial fit turned out to yield no stable result for the SCIAMACHY data set. The reason for this is a combination of two effects, namely i) the SCIAMACHY data set does not cover one full period of the annual cycle (the FTIR data set does), and ii) SCIAMACHY data are showing a higher scatter than the FTIR data. It can bee seen from Fig. 3, that the slope of the linear fits of both data sets agree quite well. Table 1 shows the errors for the slopes of these linear fits for both FTIR and SCIAMACHY data sets, which were calculated using conservative error approximations for the daily means. It can be seen, that also for SCIAMACHY data the error of the slope is significantly smaller than the value of the slope itself and the regression coefficient is reasonably good $(R=-0.7)$. This means that the obtained negative slope, which is due to the annual cycle, can be retrieved in a statistically significant manner, from SCIAMACHY WFMD data, given the considered selection radius of SCIAMACHY pixels of $2000 \mathrm{~km}$ around the Zugspitze.

The question to be addressed now is, what the minimum selection radius is, in order to obtain the negative slope in a statistically significant manner. Table 1 shows the regression results for a reduced selection radius of $1000 \mathrm{~km}$. Now, the error of the slope is comparable to the absolute value of the slope. I.e., the negative slope, being a signature of the CO annual cycle, can no longer be retrieved in a statistically significant manner from the SCIAMACHY data. So our finding is, that a minimum selection radius of $1000-2000 \mathrm{~km}$ around Zugspitze is necessary, in order to retrieve the negative slope due to the $\mathrm{CO}$ annual cycle in a statistically significant manner from WFMD SCIAMACHY data.
Finally, we investigate, whether the information content in the SCIAMACHY data as to the annual cycle could be increased by including cloud flagged pixels also into the daily average. This question arises, since the cloud clearing algorithm applied is rather conservative (Buchwitz et al., 2004). Table 1 shows the result for the case of a 1000-km selection radius. In fact, including cloud flagged pixels does essentially not change the fit quality (slope error and $R$ ). This confirms that the cloud clearing algorithm is rather conservative.

\section{Conclusions}

Solar FTIR measurements at the Permanent GroundTruthing Station Zugspitze $\left(47.42^{\circ} \mathrm{N}, \quad 10.98^{\circ} \mathrm{E}\right.$, $2964 \mathrm{~m}$ a.s.l.), Germany were used to validate the ENVISAT/SCIAMACHY Scientific Data Product for total column $\mathrm{CO}$ retrieved at the University of Bremen, i.e., the near infrared WFM-DOAS ver. 0.4 product.

The CO total column averaging kernels of the groundbased FTIR technique (integrated profile retrievals) turned out to be nearly identical to the SCIAMACHY WFMD kernels, which both maintain a nearly uniform sampling down to the lower troposphere with only minor differences at higher altitudes. Therefore a direct comparison of columns is possible without introducing significant intercomparison errors from differing smoothing errors.

In order to reduce the impact of varying ground altitudes of the different satellite pixels used for intercomparison, a new approach has successfully been explored. I.e., SCIAMACHY WFMD columns have been normalized to dry air columns, which have additionally been normalized to their overall average, and these anomalies then been compared to the ground FTIR column anomalies, to make both satellite and ground data sets comparable.

The infrared WFMD column retrievals include an empirical scaling factor of 0.5 which resulted from an adaptation to MOPITT data, therefore it is no issue to validate their overall absolute accuracy (note that recent investigations indicate that the retrieval can be significantly improved, e.g., by using a different spectral fitting window, essentially eliminating the need for a scaling factor for future versions of WFMD CO columns). Rather, focus was put on validating relative accuracy, i.e., investigating to what extent the quality of SCIAMACHY data (precision limited by spectral noise and systematic spectral residuals) allows to reproduce the actual variability of the $\mathrm{CO}$ columns, which is mainly dominated by the annual cycle, in a statistically significant manner. For this purpose, the annual cycle found by the Zugspitze FTIR column measurements $(\approx 10 \%$ amplitude $)$ was compared to the available time series of SCIAMACHY WFMD columns (i.e., January-October 2003) using daily mean pixel averages calculated from a stepwise increased selection radius around the Zugspitze. The resulting trade off was investigated between 
reducing the scatter in SCIAMACHY data by improving the statistics and introducing additional variabilities from emission sources. It was demonstrated that an increasing selection radius helps in reducing the scatter of $\mathrm{CO}$. As a result it was found that, in order to obtain a statistically significant linear fit to the $\mathrm{CO}$ annual cycle $(\approx 10 \%$ amplitude) from SCIA WFMD data, all pixels within a radius of at least 1000 $2000 \mathrm{~km}$ around Zugspitze had to be averaged for each day.

In an upcoming study, when a final (maximum) set of CO columns will have been retrieved from all exploitable SCIAMACHY measurements of one year, it will be interesting to further investigate, whether also higher order momenta of the inter-annual variability (sinusoidal cycle, column anomalies) can be retrieved from SCIAMACHY data.

Acknowledgements. The authors like to thank A. Rockmann (IMK-IFU) for maintaining the Zugspitze FTIR measurements, W. Stremme (IMK-IFU) for performing the averaging kernel calculations, and R. de Beek (Univ. Bremen) for performing WFMDOAS retrievals. This work was funded within the German SCIAMACHY validation program (GCVOS) by BMBF/DLR via contract DLR 50 EE 0007 and by the EC within the project UFTIR (contract EVK2-CT-2002-00159). This work is part of the ECNetwork of Excellence ACCENT-TROPOSAT-2.

Edited by: U. Platt

\section{References}

Bayerisches Landesamt für Umweltschutz, Luftreinhaltung, Langzeitverläufe, http://www.bayern.de/lfu/luft/langzeit/index. html, 2005.

Bovensmann, H., Burrows, J. P., Buchwitz, M., Frerick, J., Noël, S., Rozanov, V. V., Chance, K. V., and Goede, A.: SCIAMACHY Mission Objectives and Measurement Modes, J. Atmos. Sci., 56, 127-150, 1999.

Buchwitz, M. and Burrows, J. P.: Retrieval of $\mathrm{CH}_{4}, \mathrm{CO}$, and $\mathrm{CO}_{2}$ total column amounts from SCIAMACHY near-infrared nadir spectra: Retrieval algorithm and first results, in: Proc. SPIE 5235, Remote Sensing of Clouds and the Atmosphere VIII, edited by: Schäfer, K. P., Comeron, A., Carleer, M. R., and Picard, R. H., 375-388, 2004.

Buchwitz, M., de Beek, R., Bramstedt, K., Noël, S., Bovensmann, H., and Burrows, J. P.: Global carbon monoxide as retrieved from SCIAMACHY by WFM-DOAS, Atmos. Chem. Phys., 4, 19451960, 2004, SRef-ID: 1680-7324/acp/2004-4-1945.

Buchwitz, M., de Beek, R., Burrows, J. P., Bovensmann, H., Warneke, T., Notholt, J., Meirink, J. F., Goede, A. P. H., Bergamaschi, P., Körner, S., Heimann, M., and Schulz, A.: Atmospheric methane and carbon dioxide from SCIAMACHY satellite data: Initial comparison with chemistry and transport models, Atmos. Chem. Phys., 5, 941-962, 2005a,

SRef-ID: 1680-7324/acp/2005-5-941.

Buchwitz, M., de Beek, R., Noël, S., Burrows, J. P., Bovensmann, H., Bremer, H., Bergamaschi, P., Körner, S., and Heimann, M.: Carbon monoxide, methane and carbon dioxide columns retrieved from SCIAMACHY by WFM-DOAS: year 2003 initial data set, Atmos. Chem. Phys. Discuss., 5, 1943-1971, 2005b, SRef-ID: 1680-7375/acpd/2005-5-1943.
Deeter, M. N., Emmons, L. K., Francis, G. L., Edwards, D. P., Gille, J. C., Warner, J. X., Khattatov, B., Ziskin, D., Lamarque, J.-F., Ho, S.-P., Yuding, V., Attie, J.-L. Packman, D., Chen, J., Mao, D., and Drummond, J. R.: Operational carbon monoxide retrieval algorithm and selected results for the MOPITT instrument, J. Geophys.Res., 108, 4399-4409, 2003.

IPCC, IPCC Third Assessment: Climate Change 2001, The Scientific Basis, Intergovernmental Panel of Climate Change (http: //www.ipcc.ch/), 2001.

Pougatchev, N. S. and Rinsland, C. P.: Spectroscopic study of the seasonal variation of carbon monoxide vertical distribution above Kitt Peak, J. Geophys. Res., 100, 1409-1416, 1995.

Pougatchev, N. S., Connor, B. J., and Rinsland, C. P.: Infrared measurements of the ozone vertical distribution above Kitt Peak, J. Geophys. Res., 100, 16 689-16697, 1995.

Rinsland, C. P., Mahieu, E., Zander, R., and Demoulin, P.: Free tropospheric $\mathrm{CO}, \mathrm{C}_{2} \mathrm{H}_{6}$, and $\mathrm{HCN}$ obove central Europe: Recent measurements from the Jungfraujoch station including the detection of elevated columns during 1998, J. Geophys. Res., 105, 24 235-24 249, 2000.

Rodgers, C. D.: Characterization and Error Analysis of Profiles Retrieved From Remote Sounding Measurements, J. Geophys. Res., 95, 5587-5595, 1990.

Rothmann, L. S., Barbe, A., Benner, D. C., Brown, L. R., CamyPeyret, C., Carleer, M. R., Chance, K., Clerbaux, C., Dana, V., Devi, V. M., Fayt, A., Flaud, J. M., Gamache, R. R., Goldman, A., Jacquemart, D., Jucks, K. W., Lafferty, W. J., Mandin, J. Y., Massie, S. T., Nemtchinov, V., Newnham, D. A., Perrin, A., Rinsland, C. P., Schroeder, J., Smith, K. M., Smith, M. A. H., Tang, K., Toth, R. A., Vander-Auwera, J., Varanasi, P., and Yoshino, K.: The HITRAN molecular spectroscopic database: edition of 2000 including updates through 2001, J. Quant. Spectrosc. Radiat. Transfer, 82, 5-44, 2003.

Sussmann R., and Schäfer, K.: Infrared spectroscopy of tropospheric trace gases: combined analysis of horizontal and vertical column abundances, Appl. Opt., 36, 735-741, 1997.

Sussmann, R.: Ground-based Fourier transform spectrometry at the NDSC site Zugspitze: Geophysical products for satellite validation, in: Proceedings of the European Symposium on Atmospheric Measurements from Space, ESTEC, Noordwijk, The Netherlands, 18-22 January 1999, WPP-161, 2, 661-664, 1999.

Yurganov, L. N., Blumenstock, T., Grechko, E. I., Hase, F., Hyer, E. J., Kasischke, E. S., Koike, M., Kondo, Y., Kramer, I., Leung, F.-Y., Mahieu, E., Mellqvist, J., Notholt, J., Novelli, P. C., Rinsland, C. P., Scheel, H.-E., Schulz, A., Strandberg, A., Sussmann, R., Tanimoto, H., Velazco, V., Zander, R., and Zhao, Y.: A Quantitative Assessment of the 1998 Carbon Monoxide Emission Anomaly in the Northern Hemisphere Based on Total Column and Surface Concentration Measurements, J. Geophys. Res., 109, D15305, doi:10.1029/2004JD004559, 2004.

Yurganov, L. N., Duchatelet, P., Dzhola, A. V., Edwards, D. P., Hase, F., Kramer, I., Mahieu, E., Mellqvist, J., Notholt, J., Novelli, P. C., Rockmann, A., Scheel, H. E., Schneider, M., Schulz, A., Strandberg, A., Sussmann, R., Tanimoto, H., Velazco, V., Drummond, J. R., and Gille, J. C.: Increased Northern Hemispheric carbon monoxide burden in the troposphere in 2002 and 2003 detected from the ground and from space, Atmos. Chem. Phys., 5, 563-573, 2005,

SRef-ID: 1680-7324/acp/2005-5-563. 